\title{
Development of the Joints for ITER Central Solenoid
}

N. N. Martovetsky, S. J. Kenney, J. R. Miller

July 20,2010

Applied Superconductivity Conference Washington, DC, United States August 1, 2010 through August 6, 2010 
This document was prepared as an account of work sponsored by an agency of the United States government. Neither the United States government nor Lawrence Livermore National Security, LLC, nor any of their employees makes any warranty, expressed or implied, or assumes any legal liability or responsibility for the accuracy, completeness, or usefulness of any information, apparatus, product, or process disclosed, or represents that its use would not infringe privately owned rights. Reference herein to any specific commercial product, process, or service by trade name, trademark, manufacturer, or otherwise does not necessarily constitute or imply its endorsement, recommendation, or favoring by the United States government or Lawrence Livermore National Security, LLC. The views and opinions of authors expressed herein do not necessarily state or reflect those of the United States government or Lawrence Livermore National Security, LLC, and shall not be used for advertising or product endorsement purposes. 


\title{
Development of the Joints for ITER Central Solenoid
}

\author{
Nicolai N. Martovetsky, Steven .J. Kenney and John R. Miller
}

\begin{abstract}
The ITER Central Solenoid has 36 interpancake joints and 12 bus joints in the magnet. The joints are required to have resistance below $4 \mathrm{nOhm}$ at $45 \mathrm{kA}$ at $4.5 \mathrm{~K}$. The interpancake joints will have to withstand a significant cyclic tensile strain during ITER operation. The joints are located at the OD of the magnet embedded in the winding pack and therefore need to be compliant with the rest of the winding pack to avoid excessive stress.

The US ITER Project Office is carrying out a program for joints development in order to establish fabrication process and also characterize electrical and mechanical performance of the joints in a special Joint Test Apparatus.

Status of the joint development and test results are presented and discussed in the paper.
\end{abstract}

Index Terms - Superconducting cables, superconducting magnets, superconducting transformers.

\section{INTRODUCTION}

$\mathrm{T}$ HE Central Solenoid (CS) consists of six pancake wound modules. Each module has 6 hexa-pancakes and one quadra-pancake that need to be electrically joined within the space of the winding pack. The interpancake joint is one of the most critical components of the CS Modules. Failure of one of the joints makes the whole CS unusable.

Two options for the interpancake joints have been under development - butt joint and a sintered joint.

The CS design originally had a butt joint as the baseline compact joint [1]. A soldered version of a lap joint was dismissed due to doubling of the cooling lines for cooling the joint and significant increase (basically double) of the joint volume. Later, in 2007, a sintered joint was introduced, inspired by the ENEA joint development [2].

Each of the options has its attractive features. The butt joint is completed after heat treatment and therefore allows parallel insulation application and shorter fabrication schedule. But it is not forgiving to misalignment and requires very delicate handling.

The sintered joint is completed before heat treatment and therefore requires handling of the full $100 \mathrm{t}$ module through

Manuscript received 3August 2010. This work performed under the auspices of the U.S. Department of Energy by Oak Ridge National Laboratory under contract DE-AC05-00OR22725 and by Lawrence Livermore National Laboratory under Contract DE-AC52-07NA27344.

N. Martovetsky is with Lawrence Livermore National Laboratory, on assignment to Oak Ridge National Laboratory, ORNL, USIPO, 1055 Commerce Park, 37831, phone 865-576-2100, fax 865-574-8393, e-mail: martovetskyn@ornl.gov

S. Kenney is with ORNL, kenneys@usiter.org and J. Miller is retired johnrichardmiller@me.com heat treatment and insulation, which is not favorable for schedule and complexity of the assembly tools. However, it is less risky in fabrication, since after assembly it needs no handling.

From the performance stand point, the butt joint is a proven solution that did not cause any problems during operation of the CSMC Outer Module in JAEA, Naka Japan. The sintered joint with cut or partially cut subcables generates an inevitably nonuniform current distribution, which is a concern that is very difficult to qualify.

\section{ButT JoInt DEVELOPMENT}

The butt joint is a diffusion bond between tightly compacted cables after heat treatment and cutting and polishing the ends. The CS butt joint is the extension from the butt joint developed by JAERI for the CS Model Coil Outer Module [3]. However, there are several differences in fabrication: a) the butt joining tool needs to be assembled and sealed around connecting conductors, and b) the straight section where the joint is made is very short in order to prevent the joint to "bulge" from the winding pack too much. There is a difference in operation - the main difference is that there is a tensile strain across the joint interface and the magnetic field is mostly parallel to the joint interface, as opposed to be along the conductor in the CSMC joints.

We built a Butt joint fabrication system that provides all necessary conditions for reliable bonding. The butt joint is formed on the heat treated cables at the following conditions: butt-to-butt pressure $=25-30 \mathrm{MPa}$, vacuum pressure $\leq 5 \mathrm{mtorr}$ $(0.5 \mathrm{~Pa})$, temperature at the interface $=700-750 \mathrm{C}$. The bonding time was established to be 70 minutes. It is essential to have full contact over the joining area, otherwise bonding does not occur.

The system has a DAS and a control rack, relief valve and interlocked shut off valve to protect the turbo pump in the event of loss of vacuum in the chamber.

Although the butt-joint is designed to meet electrical specifications, it must also meet the demanding cyclic mechanical stress requirements that are addressed here.

First, we fabricated several samples in order to estimate a metallurgical bond of the joint at the interface. Then, we fabricated four straight samples and subjected them to cyclic and destructive loading and metallurgical evaluation of the fracture. All four prototype samples have been successfully tension-fatigue tested at $77 \mathrm{~K}$ (cable strain $\geq 0.24 \%$, cable stress $\geq 15 \mathrm{MPa}, \mathrm{R}=0.1$ ) to 60,000 cycles with no failures. This constitutes more than double of expected strain in operation. 
Three of the four have been post-fatigue tensile tested to failure to confirm that an average post-fatigue tensile strength of the joint occurs at a cable stress rating of $>60 \mathrm{MPa}$. The fourth sample has been sectioned for metallographic inspection. The tests also provided an opportunity to measure the $77 \mathrm{~K}$ stress-strain behavior of the superconducting cables, which is also presented here.

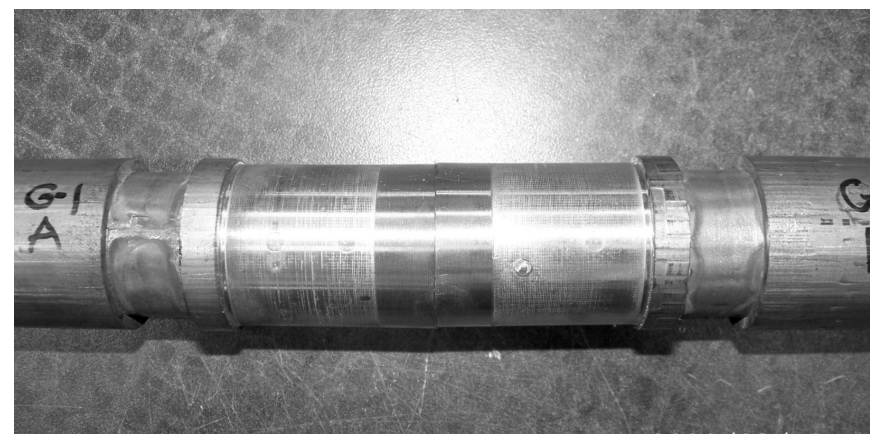

Fig. 1. CS butt joint

TABLE 1 ButT JoInt STRENGTH AFter CyCLING

\begin{tabular}{cccc}
\hline \hline $\begin{array}{c}\text { Sample } \\
\text { ID }\end{array}$ & $\begin{array}{c}\text { Cycling } \\
\text { stress, MPa }\end{array}$ & $\begin{array}{c}\text { Post fatigue } \\
\text { tensile } \\
\text { strength, } \mathbf{k N}\end{array}$ & $\begin{array}{c}\text { Cable stress at } \\
\text { failure, MPa }\end{array}$ \\
\hline 1 & 15 & 29.4 & 62.9 \\
2 & 21.4 & $\mathrm{n} / \mathrm{a}$ & $\mathrm{n} / \mathrm{a}$ \\
3 & 15 & 38 & 81.3 \\
4 & 15 & 29 & 62 \\
\hline \hline
\end{tabular}

The sample 2 was not fractured in order to explore metallurgical bond. Sectioned and polished samples showed good adherence of the wires to the copper interface sheet when it was fractured in the post-fatigue tension test.

\section{SinTERED JOINT DEVELOPMENT}

We liked the ENEA (Frascati) group idea of having the joint with the same cross section as the regular cable, but we slightly modified the design and considered two options. The simplest was a three-finger design in which every other subcable was completely cut, and the remaining void was filled with a subcable from the opposite conductor as shown in Fig. 2.

Such a concept of a joint is simpler than that presented in the original proposal, but it would potentially have worse current-distribution nonuniformity, which would be difficult to quantify or assess. In the worst-case scenario, only half of the cable would carry the full current, which might cause stability problems. To partially suppress such distribution nonuniformity, one could trace the subcables and make connections between the subcables in such a manner that current was forced to cross the boundary between the subcables. But such a measure would require identification of the subcables and still would not guarantee uniform distribution, although it would improve distribution.

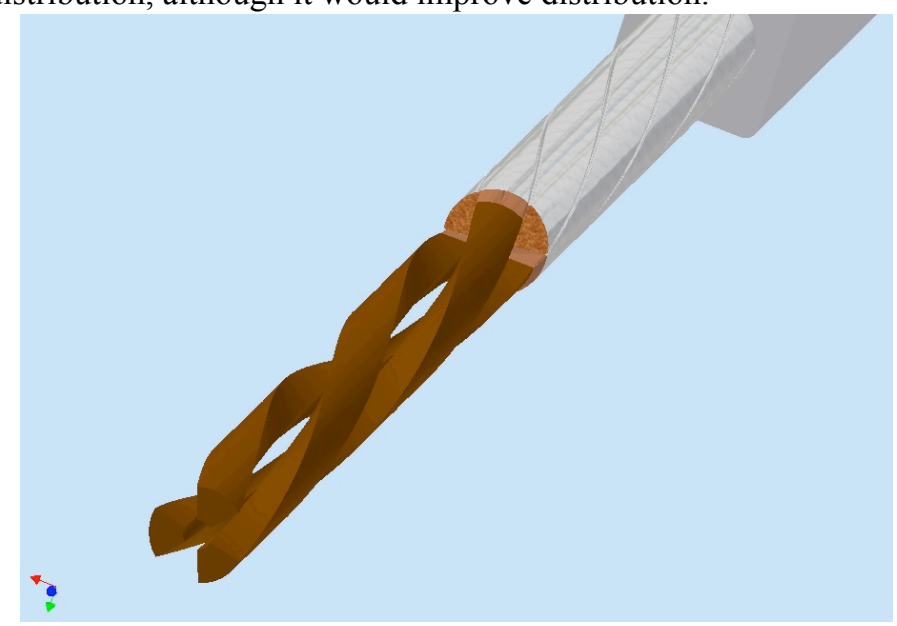

Fig. 2. Three-finger concept of the sintered joint

A slightly more complicated but much more electrodynamically reliable option would be a six-finger design (Fig. 3). In this option the current nonuniformity would be contained on the level of a subcable, rather than on the level of the cable as in the three-finger or ENEA design.

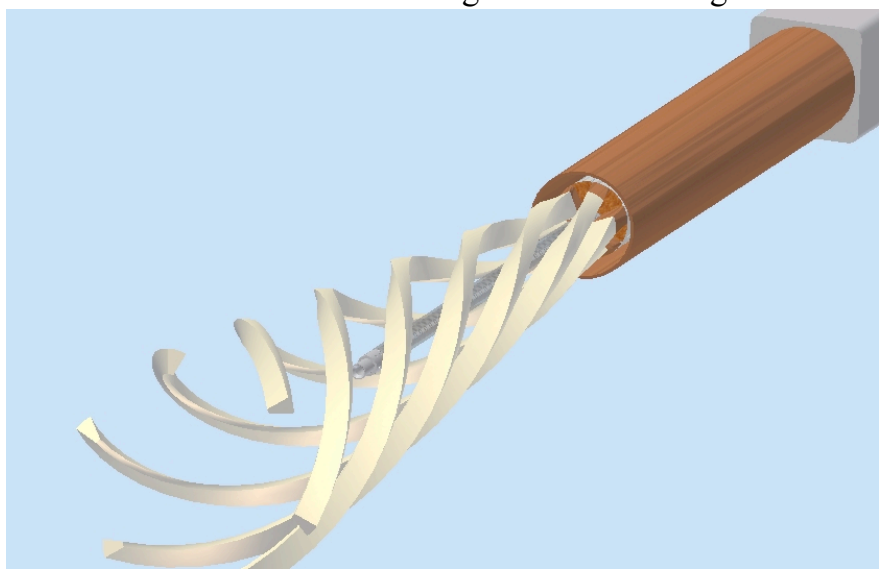

Fig. 3. Six-finger design of a spliced joint.

\section{A. Sintered joint prototype}

In order to address the fabrication steps for sintered joint, we fabricated a prototype $3 \times 3$ full scale sintered joint. One of the most critical operations addressed in the study is common for both types of the joint, namely close out welds. The intention of the restoring the jacket is to avoid stress concentration, which occurs if jacket thickness experience rapid change in the cross section. That is why it is advantageous to maintain cross section of the joint the same as the regular conductor.

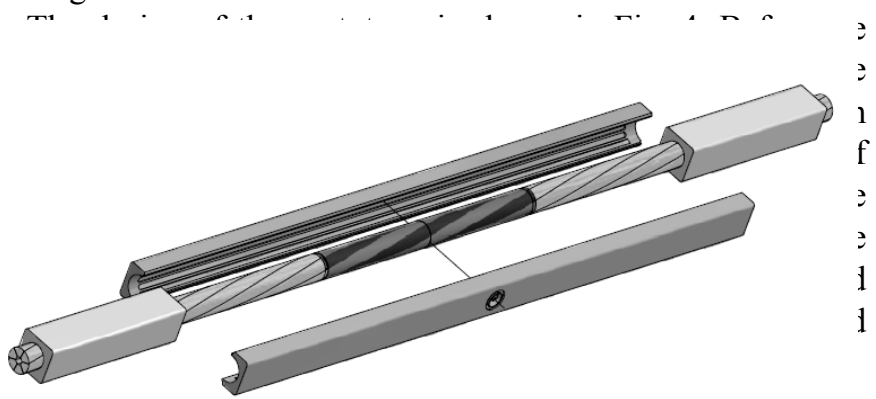


higher. Moreover, the quality of the welds with multiple stops turned out to be unacceptable.

The time duration when this temperature exceeded the target value lasted only for 5-15 s. Having in mind that the reaction heat treatment at $650 \mathrm{C}$ lasts several days, the very short heat pulses are not important. Taking into account that the CS cable will not have internal tin strands, and there is no tin to melt, this requirement of $230 \mathrm{C}$ during welding is not critical either before or especially after heat treatment. When this requirement was removed, we achieved a good quality of full penetration welds everywhere.

\section{B. Sintering studies}

The sintered joint low resistance relies on a good quality of sintering among the strands and cable and the copper sleeve. From the past joint development it is known that for good sintering a compaction of the cable shall be down to $20 \%$ void or tighter. Surface condition of the strands is also important.

According to the fabrication schedule, some of the joints will be assembled many months before heat treatment. Exposure to atmospheric oxygen and moisture is a concern for good quality of sintering.

Our studies showed that even though oxidation does take place, the surface recovers and restores its virgin metallic appearance during heat treatment in the inert gas.

\section{ANALYSIS OF HYDRAULIC IMPEDANCE OF THE JOINTS}

Exact location of the joints and helium outlets is a difficult constraint. The joint receives the cooling from helium injected at the inner diameter. If hydraulic impedance of the joint is insignificant in comparison with the impedance of the hydraulic path of the pancake, it allows a significant relief and allows placing the helium outlet in any convenient place. We built a hydraulic model and showed that the impedance of the joint does not exceed $1200 \mathrm{~Pa}$, which is negligible in comparison with expected $60000 \mathrm{~Pa}(0.6 \mathrm{bar})$ of pressure drop between the inlet and outlet. This conclusion is valid for both types of joint, sintered and butt joint.

\section{JOINT Test Apparatus}

To qualify joints we designed and built a Joint Test Apparatus (JTA). The principle element of the JTA is a superconducting transformer, see Fig.5. The inner, primary, coil is driven by a power supply. The inductively coupled inner coil induces a current in the outer coil, which is a singleturn racetrack with the joint, and then the power supply holds a constant current in the inner coil. The induced current decays on the joint resistance, and we measure the decay time, which is

$$
\tau_{\text {decay }}=\frac{L}{R_{\text {joint }}} .
$$

We know the inductance from modeling it in the OPERA software, so by measuring the decay time, we can determine joint resistance. We also measure the voltage drop across the joint and the magnetic field with two calibrated Hall probes with resistance on both sides of the test sample, which gives a fairly accurate reading of the current in the test sample. Knowing voltage across the joint and the current we obtain direct measurement of the resistance. So we have two independent ways of measuring joint resistance.

Self-inductances and coupling of the JTA are provided in Table 2. The JTA has a four-quadrant power supply that can charge and discharge the primary winding up to $200 \mathrm{~A}$ at the rate up to $8 \mathrm{~A} / \mathrm{s}$.

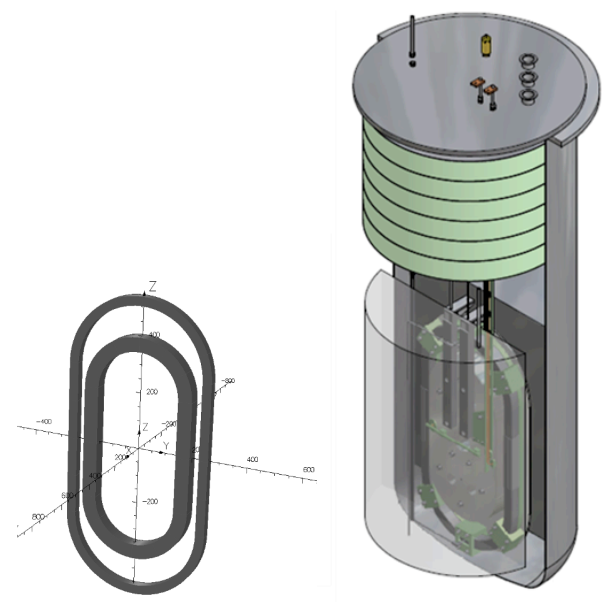

Fig. 5. Schematic of JTA transformer (left) and JTA assembled in the cryostat (right)

TABLE 2 INDUCTANCE OF THE JTA WINDINGS

\begin{tabular}{cc}
\hline \hline Inductance & Value \\
\hline $\mathrm{L}_{\text {primary }}, \mathrm{H}$ & 1.05 \\
$\mathrm{~L}_{\text {sample }}, \mathrm{H}$ & $2.15 \mathrm{e}-6$ \\
$\mathrm{M}, \mathrm{H}$ & $5.90 \mathrm{e}-4$ \\
\hline
\end{tabular}

$\mathrm{M}$ is mutual inductance

The sample is equipped with a heater to kill persistent current so every run will start in a virgin state, if desired.

In the case of a negligibly low resistance, the current in the sample will be

$$
\mathrm{I}_{\text {sample }}=\frac{M}{L_{\text {sample }}} \mathrm{I}_{\text {primary }}
$$

Thus, at $200 \mathrm{~A}$ in the primary winding the current in the sample will be $56 \mathrm{kA}$.

The current in the primary coil is measured by two Hall probes located in the area in which the effect of the field is the strongest from the sample and relatively weak from the primary winding.

To measure the joint resistance, we do not need an absolute value of the magnetic field, just the decay time.

We do need the absolute measurement of the Hall probes to measure current in the sample, so we are using calibrated sensors (although it is not the main purpose of the JTA measurements).

To reduce the amount of liquid helium used for testing, we inserted displacement bladders into the Dewar volume, shown in Fig. 5. With this measure and LN2 precooling, the total consumption of liquid helium was less than $400 \mathrm{~L}$, a 
significant amount of which could be reused by transferring the remaining liquid helium into a transport Dewar or by testing several samples consequently.

\section{FIRST TESTED RACETRACK TEST RESUlTS}

The first racetrack tested in JTA was a sintered joint with six fingers. The current decay method showed that resistance of the joint was $0.134 \mathrm{nOhm}$, which comfortably meets requirement of $4 \mathrm{nOhm}$ even after magnetoresistance is taken into account. The current in the sample was $50 \mathrm{kA}$ at $200 \mathrm{~A}$ in the primary, because persistent current was $-6 \mathrm{kA}$ in the beginning of the swing. Thus, the total induced current in the sample was $56 \mathrm{kA}$ at $200 \mathrm{~A}$ in the primary winding, exactly as expected.

Direct measurement of joint showed significantly lower resistance, but direct measurement of resistance is not as reliable since voltage taps are located on the jacket and too close to the joint, where electrical potential distribution is very tricky. We observed this abnormality during CSMC activities and joint development effort for that project [4].

\section{CONCLUSION}

Significant progress has been made in the CS joint development. Both the butt joint and sintered joint options look feasible. The sintered joint was electrically tested and showed very good performance. The butt joint showed very good mechanical properties. Two butt joint racetracks are scheduled to be electrically tested later this year. The final selection will be made after thorough consideration of technical risks, cost and schedule.

We built a very economical apparatus for joint measurements at $4 \mathrm{~K}$, which will be used for all joint types for the ITER Central Solenoid.

\section{ACKNOWLEDGMENT}

We are thankful to Magnet Development Laboratory at University of Tennessee in Knoxville, led by David (Butch) Irick, who fabricated the furnaces, CICCs, and racetrack samples. MDL performed heat treatment, machining, and welding and all other fabrication and assembly steps as required. One of UTK undergraduate students, S. Mohammed led by Professor M. Madhukar, also performed a study on the effect of moisture and oxygen on sintering of the strands (available as a separate report).

Cryomagnetics, Inc., fabricated and assembled the JTA and all necessary instrumentation and auxiliary systems and performed the tests with major contributions from A. Berryhill and E. Burkhardt.

The Russian Cabling Institute fabricated the CS cable out of Oxford and Luvata strands.

Material Evaluation and Testing, Inc., in Oak Ridge formed the conductors into the needed shape.

Barbier, Charlotte N., ORNL, performed hydraulic impedance studies.

Robert Walsh, NHMFL performed mechanical testing and metallographic evaluation of the butt joints.

\section{REFERENCES}

[1] N.N. Martovetsky, "Development of the Butt Joint for the ITER Central Solenoid”, IEEE Trans. Appl. Supercond., vol. 17, pp. 1358-1361, June 2007.

[2] A. Di Zenobio et al., "Joint Design for the EDIPO," IEEE Trans.Appl Supercond., 18(2): 192-195, June 2008

[3] Y. Takahashi, Y. Nunoya, G. Nishijima et al, "Development of 46-kA Nb3Sn Conductor Joint for ITER Model Coils", IEEE Trans. Appl. Supercond., vol. 10, No 1, pp.580-583, March 2000.

[4] N. Martovetsky, P. Michael, A. Radovinsky, C-Y Gung, "Analysis of US Preprototype Joint DC performance", Proc of 15th Int. Conference on Magnet Technology, Science Press, China, p.429-432, 1997 